\title{
Oleuropein Degradation Kinetics in Olive Leaf and Its Aqueous Extracts
}

\author{
María Esther Martínez-Navarro ${ }^{1}$, Cristina Cebrián-Tarancón ${ }^{1}\left[\right.$, José Oliva ${ }^{2}$, María Rosario Salinas ${ }^{1}(\mathbb{C}$ \\ and Gonzalo L. Alonso 1,*(D) \\ 1 Cátedra de Química Agrícola, E.T.S.I. Agrónomos y Montes, Departamento de Ciencia y Tecnología \\ Agroforestal y Genética, Universidad de Castilla-La Mancha, Avda. de España s/n, 02071 Albacete, Spain; \\ Mesther.Martinez@uclm.es (M.E.M.-N.); cristina.ctarancon@uclm.es (C.C.-T.); \\ Rosario.Salinas@uclm.es (M.R.S.) \\ 2 Departamento de Química Agrícola, Geología y Edafología, Facultad de Química, Universidad de Murcia, \\ Campus de Espinardo s/n, 30100 Murcia, Spain; josoliva@um.es \\ * Correspondence: Gonzalo.Alonso@uclm.com; Tel.: +34-967-599210; Fax: +34-967-599238
}

check for updates

Citation: Martínez-Navarro, M.E.; Cebrián-Tarancón, C.; Oliva, J.; Salinas, M.R.; Alonso, G.L. Oleuropein Degradation Kinetics in Olive Leaf and Its Aqueous Extracts. Antioxidants 2021, 10, 1963. https://doi.org/ $10.3390 /$ antiox 10121963

Academic Editors: Juan

Fernández-Bolaños and Alejandra Bermudez-Oria

Received: 25 November 2021 Accepted: 6 December 2021 Published: 8 December 2021

Publisher's Note: MDPI stays neutral with regard to jurisdictional claims in published maps and institutional affiliations.

Copyright: (c) 2021 by the authors. Licensee MDPI, Basel, Switzerland. This article is an open access article distributed under the terms and conditions of the Creative Commons Attribution (CC BY) license (https:// creativecommons.org/licenses/by/ $4.0 /)$.

\begin{abstract}
Although olives leaves are currently considered a waste material from oil mills, they have great potential to be transformed into by-products due to their high oleuropein content. Oleuropein is a glycoside precursor of hydroxytyrosol, which is the phenolic compound with the highest antioxidant capacity in nature and which is associated with multiple health benefits. For this reason, the demand for oleuropein is growing in the pharmaceutical, cosmetic and food sectors. The objective of this study is to determine the stability of oleuropein in olive leaves from oil mills in solid and aqueous forms under different conditions of temperature, relative humidity and lighting. The results indicate that the degradation of oleuropein conforms well to first-order kinetics. The rate constants at the temperatures tested in the aqueous extracts indicate activation energies from $\mathrm{RT}_{1}$ to $80{ }^{\circ} \mathrm{C}$ and from $7{ }^{\circ} \mathrm{C}$ to $14^{\circ} \mathrm{C}$, as the degradation reactions were different in these ranges. Furthermore, olive leaf powder stored at any temperature with an $\mathrm{RH} \geq 57 \%$ showed greater stability after six months, which is an encouraging result for the storage and transformation of this waste in oil mills.
\end{abstract}

Keywords: by-product; kinetics; liquid extract; oleuropein; olive leaves; storage

\section{Introduction}

Olive leaves (Olea europaea L.) are still considered a waste product produced by oil mills, especially given the pruning and maintenance labours in grove olive. During the pruning season, 1.5-3 annual tons of leaves per ha can be collected, while the weight of leaves in an oil mill ranges from approximately 0.075 to 0.15 annual tons per ha [1,2]. Traditionally, these waste products are burned or used for animal feed. However, the olive leaves are rich in polyphenols, bioactive compounds with beneficial health effects, which should be used as secondary raw materials for pharmaceutical, cosmetic and food sectors $[3,4]$. These health benefits are due to the composition in bioactive compounds, mainly oleuropein. The latter is the most abundant of these compounds and, to a lesser extent, hydroxycinnamic-acid derivatives such as verbascoside; simple phenolic alcohols, such as hydroxytyrosol and tyrosol; and flavonoids, such as apigenin 7-O-glucoside and diosmetin-7-O-glucoside. Oleuropein is the glycoside formed between a molecule of elenolic acid linked to hydroxytyrosol by an ester bond and to a molecule of glucose by a glycosidic bond. Therefore, oleuropein has been identified as the most suitable precursor to hydroxytyrosol, which has a wide range of biotic and pharmacological uses [5]. The antioxidant properties of products and by-products from an olive tree have been categorically proven, demonstrating that oleuropein and hydroxytyrosol are especially potent scavengers of superoxide anion and other reactive species [6]. Hydroxytyrosol is considered the most powerful antioxidant compound after gallic acid and one of the most powerful 
antioxidant compounds alongside phenolic and oleuropein compounds [7]. Due to its high antioxidant capacity, it is a potential therapeutic, antithrombotic, cardioprotective, antitumor microbicide and anti-inflammatory agent [8-12]. Furthermore, a health claim on olive oil polyphenols from the European Food Safety Authority states that they contribute to the protection of blood lipids from oxidative stress [13]. For these reasons, such compounds have attracted great interest from the pharmaceutical, cosmetic and food sectors.

Oleuropein, hydroxytyrosol and other olive leaf bioactive compounds are soluble in water, which gives oil mills great potential to obtain aqueous extracts rich in bioactive compounds and possibly transform this waste into a by-product. There is also the possibility of transforming the leaves in a solid form into by-products

However, no studies have focused on how the bioactive compounds in the olive leaf could evolve if they were transformed into a by-product in the olive mill and stored there. Thus, the aim of this study is to determine the stability of the oleuropein content in olive leaves derived from oil mills in both solid and aqueous forms under different conditions of temperature, relative humidity and lighting.

\section{Materials and Methods}

\subsection{Plant Material}

Olive leaves (Olea europaea L.) were obtained from the processing line of an oil mill located in the Castilla-La Mancha region of southwest Spain (altitude of $910 \mathrm{~m}, 38^{\circ} 41^{\prime} 8^{\prime \prime} \mathrm{N}$ latitude and $2^{\circ} 29^{\prime} 26^{\prime \prime} \mathrm{W}$ longitude) in November 2020. The leaves were air-dried in an uncontrolled room temperature in the dark for seven days. The samples were then stored at room temperature until use.

The dried leaves were ground in a knife mill (ARES FML-2000; Filtra Vibración, Barcelona, Spain) for $30 \mathrm{~s}$ and passed through a sieve (500 mesh) until at least $95 \%$ of the total weight had passed through, yielding olive leaf powder (solid form).

\subsection{Storage Conditions}

The solid storage conditions were based on those used by Moratalla-López et al. (2019) [14]: room temperature $\left(\mathrm{RT}_{\mathrm{s}} ; 22.8 \pm 1.9{ }^{\circ} \mathrm{C}\right)$ and $40{ }^{\circ} \mathrm{C}$; three relative humidities (RH; 23\%, 57\% and 75\%); and two lighting conditions (natural light and darkness). The laboratory room was set to $22^{\circ} \mathrm{C}$, and the laboratory oven was set to $40^{\circ} \mathrm{C}$. Each laboratory oven held three hermetically sealed boxes containing different saturated solutions (potassium acetate, sodium bromide and sodium chloride) to produce $23 \%, 57 \%$ and $75 \%$ $\mathrm{RH}$, respectively. Twelve glass petri dishes measuring $6 \mathrm{~cm}$ in diameter and $0.2 \mathrm{~cm}$ thick were used with $15 \mathrm{~g}$ of olive leaf powder. The hermetically sealed boxes had dimensions of $25 \times 15 \times 7.5 \mathrm{~cm}$ (length $\times$ width $\times$ height). Four glass petri dishes of olive leaf powder were placed in each box and were separated from the corresponding saturated solution by a grid. In addition, two petri dishes were stored at $\mathrm{RT}_{\mathrm{s}}$ and ambient humidity.

Liquid storage conditions were $80,60,40, \mathrm{RT}_{1}\left(24 \pm 1.4^{\circ} \mathrm{C}\right), 14$ and $7^{\circ} \mathrm{C}$. Laboratory ovens were set at 80,60 and $40^{\circ} \mathrm{C}$, while the refrigerators were set at 14 and $7{ }^{\circ} \mathrm{C}$. Four bottles with $30 \mathrm{~mL}$ of aqueous olive leaf extract were stored at each temperature for high-performance liquid chromatograph with a diode-array detector (HPLC-DAD) and $\mathrm{pH}$ analyses.

\subsection{Preparation of Oleuropein-Rich Aqueous Extracts from Olive Leaves}

Aqueous extracts of olive leaves were prepared according to Martínez-Navarro et al. (2021) [4] with $25 \mathrm{~mL}$ of distilled water and $50 \mathrm{mg}$ of olive leaf powder. The mixture was extracted in a domestic microwave oven (MS-2819W; Saivod, Madrid, Spain) at 800 watts for $30 \mathrm{~s}$. For the liquid kinetics, $1 \mathrm{~L}$ of aqueous extract was prepared, which was stored under the conditions described in Section 2.2. 


\subsection{Compound Analysis}

Oleuropein from aqueous extracts was analysed according to the methodology described by Martínez-Navarro et al. (2021) [4]. These extracts were first injected into an Agilent 1200 HPLC (Palo Alto, CA, USA) equipped with a DAD (Agilent G1315D). The latter was coupled to an Agilent ChemStation (Version B.03.01) data-processing station. Separation was performed at $30{ }^{\circ} \mathrm{C}$ on a reverse-phase C18 column (Brisa LC2; $250 \mathrm{~mm} \times 4.6 \mathrm{~mm}, 5 \mu \mathrm{m}$ particle) purchased from Teknokroma (Barcelona, Spain).

In addition, the compounds generated in the kinetics process were identified using an Agilent 1290 Series II HPLC (Agilent Technologies Deutschland GmbH, Waldbronn, Germany) coupled to an Agilent 6550 Q-TOF (Agilent Technologies Deutschland GmbH, Waldbronn, Germany) with a Jet Stream dual-electrospray ionisation source. Mass spectrometry (MS) data acquisition was performed in negative scan mode. Nitrogen was used for both the drying gas and the sheath gas in the source. The capillary voltage was set to $4000 \mathrm{~V}$. The nozzle voltage was set to $500 \mathrm{~V}$, and the fragmentor voltage was set to $350 \mathrm{~V}$. The drying gas flow was set to $16 \mathrm{~L} / \mathrm{min}$ at $150{ }^{\circ} \mathrm{C}$. The sheath gas flow was set to $12 \mathrm{~L} / \mathrm{min}$ at $300{ }^{\circ} \mathrm{C}$, and the nebuliser was set to $30 \mathrm{psig}$. The scan range was set to $m / z 50-1100$ for the MS and MS/MS modes. To minimise any changes in the compounds' retention time and to avoid the formation of adducts, we used the same column, solvents, flow rates and elution gradients as were used in the HPLC-DAD analysis. The possible compounds generated in the kinetic process sought were oleuropein $\left(539.177 \mathrm{~m} / z[\mathrm{M}-\mathrm{H}]^{-}\right)$, hydroxytyrosol hexoside $\left(315.1085 \mathrm{~m} / z[\mathrm{M}-\mathrm{H}]^{-}\right)$, hydroxytyrosol $\left(153.0557 \mathrm{~m} / \mathrm{z}[\mathrm{M}-\mathrm{H}]^{-}\right)$, hydroxyoleuropein $\left(557.1719 \mathrm{~m} / z[\mathrm{M}-\mathrm{H}]^{-}\right)$, luteolin $\left(447.0933 \mathrm{~m} / z[\mathrm{M}-\mathrm{H}]^{-}\right)$, oleoside 11-methyl ester $\left(403.1246 \mathrm{~m} / z[\mathrm{M}-\mathrm{H}]^{-}\right)$, verbascoside $\left(623.1981 \mathrm{~m} / z[\mathrm{M}-\mathrm{H}]^{-}\right)$, apigenin7-glucoside $\left.(431.0984 \mathrm{~m} / z \text { [M }-\mathrm{H}]^{-}\right)$, diosmetin-7-glucoside $\left(461.1089 \mathrm{~m} / z[\mathrm{M}-\mathrm{H}]^{-}\right)$and tyrosol $\left(138.164 \mathrm{~m} / z[\mathrm{M}-\mathrm{H}]^{-}\right)$.

\subsection{Kinetics Studies}

A trial-and-error method was used to find the reaction order. If the assumed order is correct, the appropriate plot of the concentration-time data (zero-order (concentration against time), first-order (ln concentration against time), and second-order (1/concentration against time)) should be linear. The result showing the best correlation coefficient $\left(R^{2}\right)$ was selected. To obtain the kinetic parameters, from each reaction were obtained reaction order, rate constants $(k)$ and half-life periods $\left(\mathrm{t}_{1 / 2}\right)$ [15]. To perform these calculations, Excel (Office, Microsoft; 2019) was used.

\subsection{Statical Analysis}

A one-way analysis of variance (ANOVA) was performed on each determination. Mean values were compared via the Tukey test with a $95 \%$ confidence interval to determine significant differences using SPSS 23 for Windows (SPSS INC., Chicago, IL, USA). All analyses were performed in triplicate and expressed as milligrams compound per gram of olive leaf for the solid form and milligrams compound per litre aqueous extract for the liquid form.

\section{Results}

\subsection{Olive Leaf Powder}

The evolution of the oleuropein content in olive leaf powder over time is shown in Figure 1. 


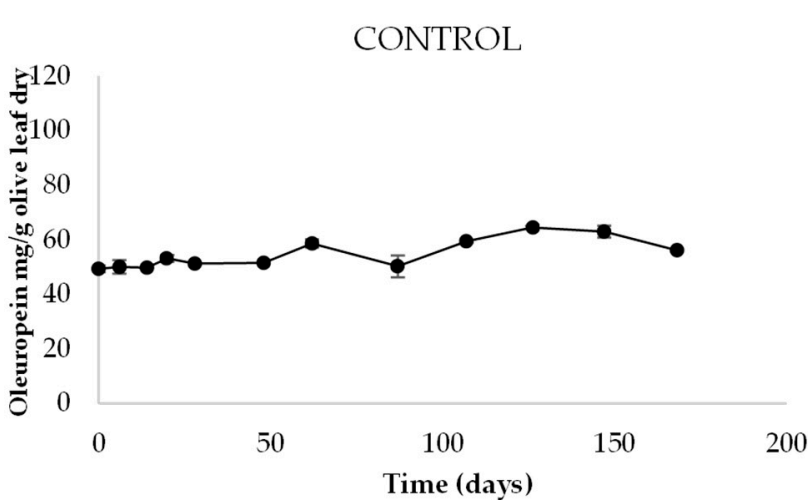

(a)

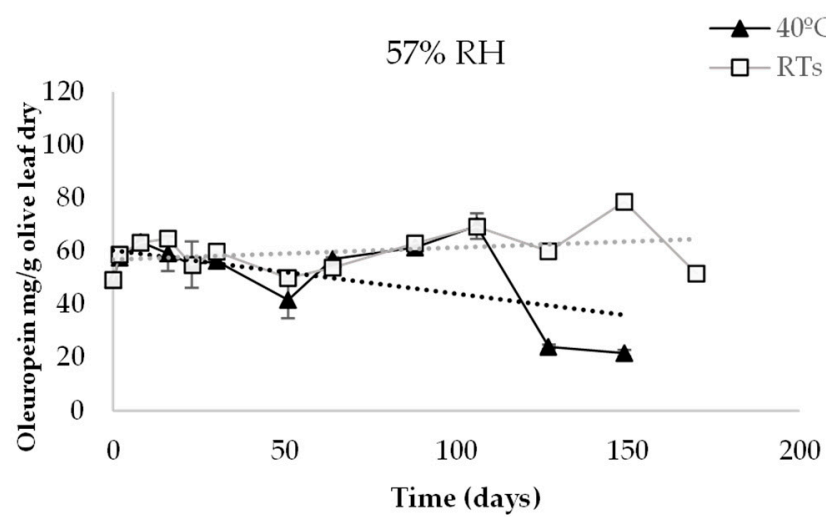

(c)

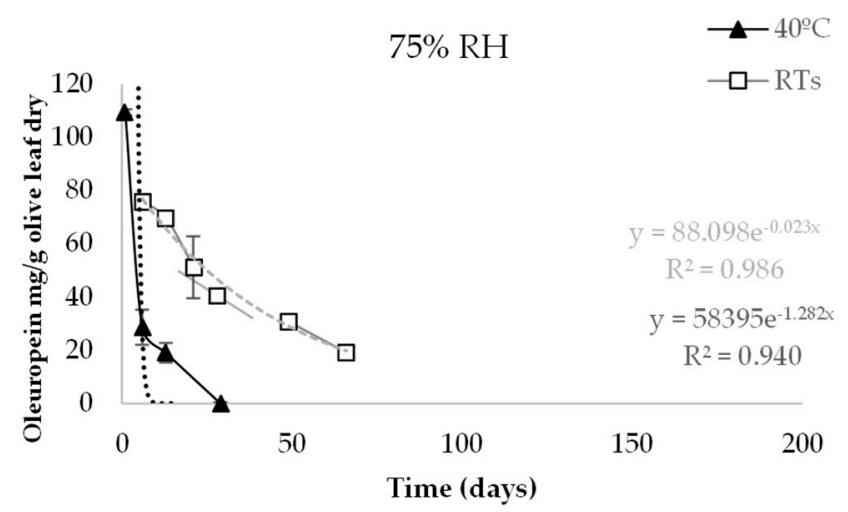

(b)

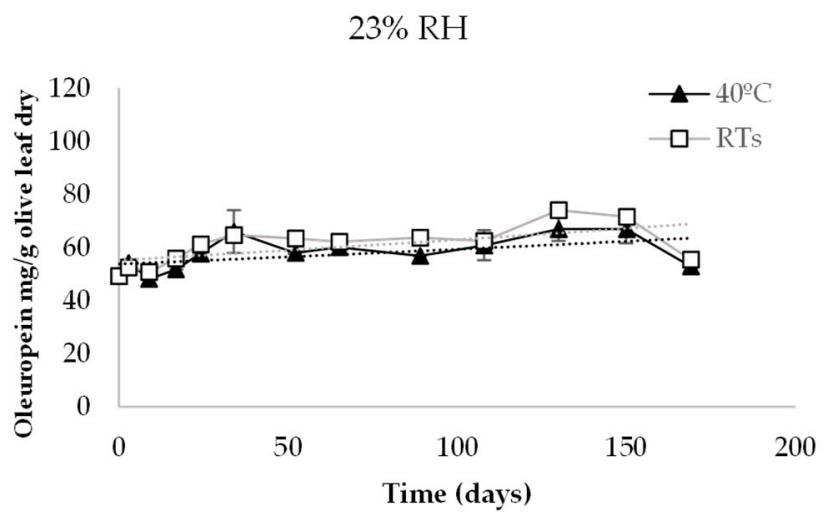

(d)

Figure 1. Mean values of oleuropein content (mg/g olive leaf) in olive leaf powder stored at different temperatures (room temperature $\left(\mathrm{RT}_{\mathrm{S}}\right)$ and $40{ }^{\circ} \mathrm{C}$ ) and relative humidities (\%RH) for 170 days: (a) Control; (b) $75 \% \mathrm{RH}$; (c) $57 \% \mathrm{RH}$; (d) $23 \% \mathrm{RH}$.

At the beginning of the experiment, the oleuropein content was analysed weekly. After a time, the analyses were carried out every three weeks. The initial oleuropein concentration in olive leaf powder was $49.33 \mathrm{mg} / \mathrm{g}$ (T0), which evolved in different ways in the studied conditions. In the control olive leaf powder, stored at $\mathrm{RT}_{\mathrm{s}}$ and environmental humidity (50\%), it was observed that all measured concentrations were higher than $\mathrm{T} 0$. The maximum oleuropein content, $65.95 \mathrm{mg} / \mathrm{g}$, was reached in the control on Day 147 . Regarding $57 \% \mathrm{RH}$, an increase in the oleuropein content was also observed after T0 both at $\mathrm{RT}_{\mathrm{s}}$ and $40{ }^{\circ} \mathrm{C}$. However, on Day 127 , the content at $40{ }^{\circ} \mathrm{C}$ decreased to $24.07 \mathrm{mg} / \mathrm{g}$, while for the same day at $\mathrm{RT}_{\mathrm{s}}$, the content was $60.03 \mathrm{mg} / \mathrm{g}$. The maximum content was $78.64 \mathrm{mg} / \mathrm{g}$ on Day 149 at $57 \% \mathrm{RH}$ and $\mathrm{RT}_{\mathrm{s}}$. Oleuropein content under conditions of $23 \%$ $\mathrm{RH}$ was the most constant of all those studied along with the control. An increase was also observed after T0, obtaining the highest content of $74.15 \mathrm{mg} / \mathrm{g}$ on Day 130 at $\mathrm{RT}_{\mathrm{s}}$.

Undoubtedly, the $75 \% \mathrm{RH}$ storage conditions most affected the oleuropein content (Figure 1b). In fewer than $24 \mathrm{~h}$, the T0 content at $40^{\circ} \mathrm{C}$ increased to $109.27 \mathrm{mg} / \mathrm{g}$, which rapidly decreased after six days to $28.58 \mathrm{mg} / \mathrm{g}$. On Day 29, the oleuropein was undetectable. The sample stored at $\mathrm{RT}_{\mathrm{S}}$ showed a more attenuated tendency. It increased from $\mathrm{T} 0$ to $75.62 \mathrm{mg} / \mathrm{g}$, while it decreased over 66 days to $19.11 \mathrm{mg} / \mathrm{g}$. On the following days, no oleuropein content was detected.

The behaviour of oleuropein contained in olive leaf at the different illuminations studied was similar in all storage conditions (data not shown).

\subsection{Aqueous Olive Leaf Extract}

The starting oleuropein concentration in the aqueous extract was $357.91 \mathrm{mg} / \mathrm{L}(45.33 \mathrm{mg} / \mathrm{g}$ dry olive leaf). Temperature influenced the evolution of the oleuropein; the points ob- 
tained fit well to an exponential equation under all storage conditions with an $\mathrm{R}^{2}$ between 0.969-0.998 (Figure 2).

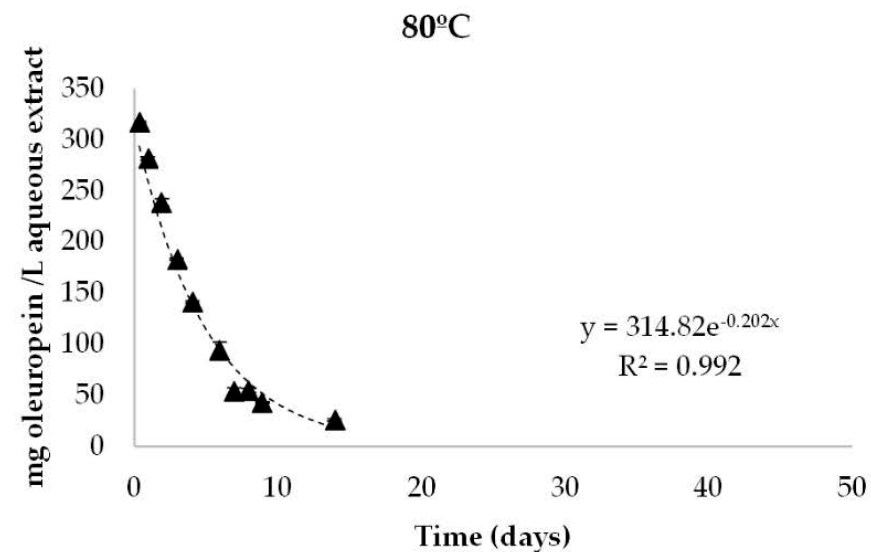

(a)

$40^{\circ} \mathrm{C}$

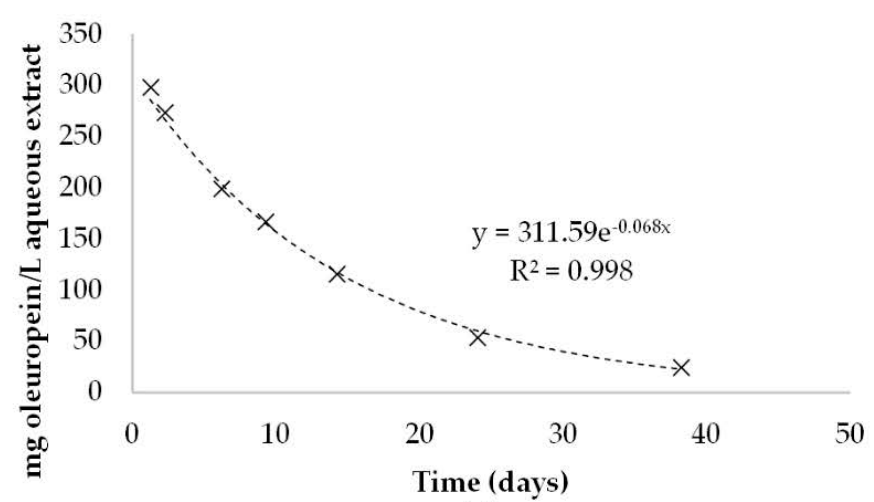

(c)

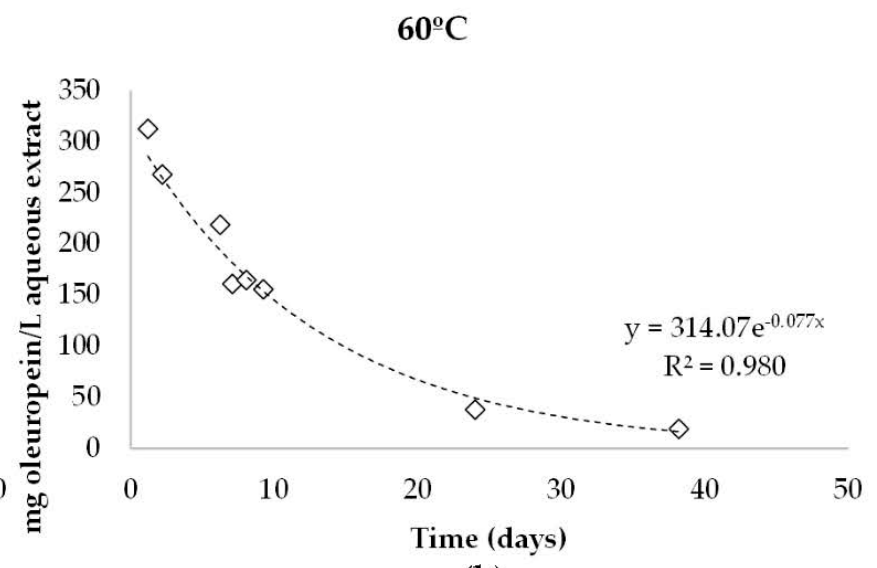

(b)

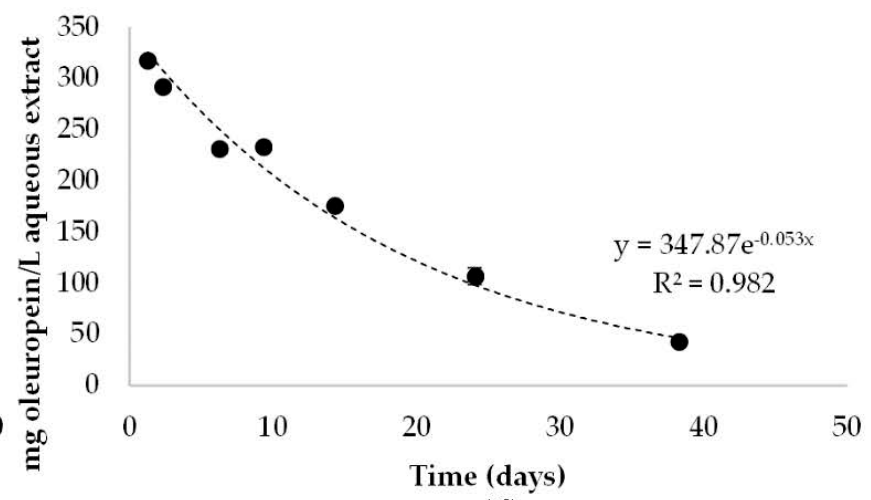

(d)

$14^{\circ} \mathrm{C}$

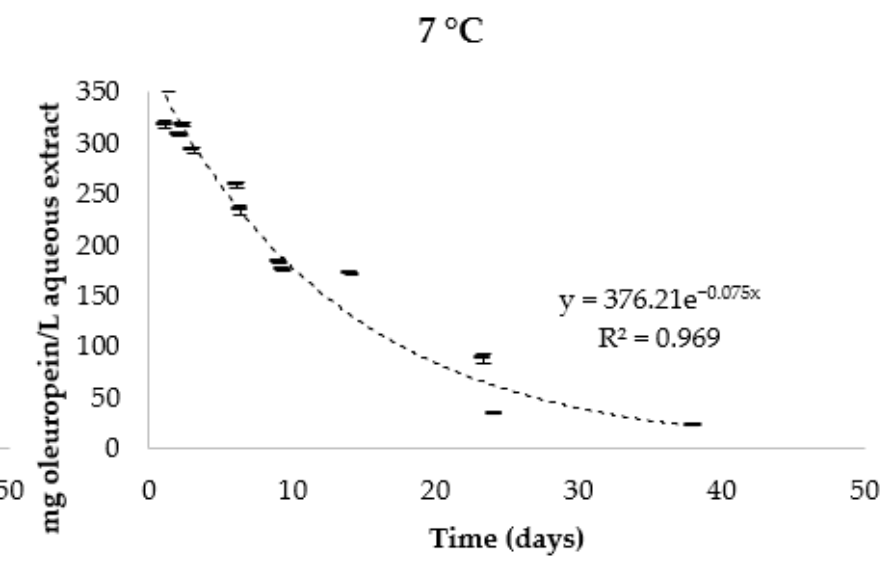

(f)

Figure 2. Mean values of oleuropein content $(\mathrm{mg} / \mathrm{L}$ aqueous extract) in aqueous extract from olive leaf stored at different temperatures for 60 days: (a) $80^{\circ} \mathrm{C}$; (b) $60^{\circ} \mathrm{C}$; (c) $40^{\circ} \mathrm{C}$; (d) $\mathrm{RT}_{1}\left(24 \pm 1.4{ }^{\circ} \mathrm{C}\right)$; (e) $14^{\circ} \mathrm{C}$; (f) $7{ }^{\circ} \mathrm{C}$. 
The $\mathrm{pH}$ of the aqueous extracts at the beginning of the experiment was 6.30. This value remained constant at warm and cold storage temperatures. However, at $80{ }^{\circ} \mathrm{C}$, a decrease in $\mathrm{pH}$ was observed down to 4.42 (Figure 3). For the other temperatures, the average $\mathrm{pH}$ was $5.83 \pm 0.29$.

\section{$80{ }^{\circ} \mathrm{C}$}

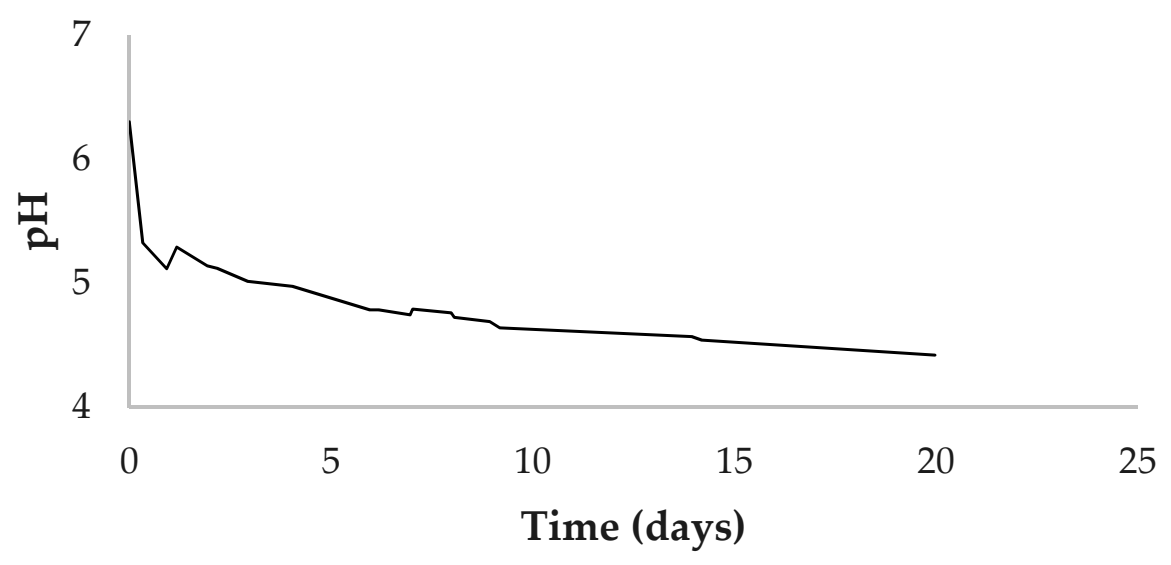

Figure 3. Evolution of mean $\mathrm{pH}$ values of aqueous extract at $80^{\circ} \mathrm{C}$.

\subsection{Evolution of Compounds}

It was observed that the chemical nature of the compounds in the aqueous extract evolved over time, especially when the conditions were the most adverse. On the other hand, the olive leaf powder in solid form was more stable than the aqueous extracts, except for those stored at $75 \% \mathrm{RH}$.

Figure 4 shows the evolution of the liquid extract compounds at $80^{\circ} \mathrm{C}$. The oleuropein was split into two peaks due to the different polarity of the conformational forms of the structure, which was observed by Serrano-Díaz et al. (2014) [16] and others [17] in glycosylated phenolic compounds from plant material. At the beginning (Figure 4a), oleuropein and its conformational isomer $\left(539.1766 \mathrm{~m} / z[\mathrm{M}-\mathrm{H}]^{-}\right.$experimental (exp.) $)$were predominant, followed by hydroxyoleuropein $\left(555.1735 \mathrm{~m} / z[\mathrm{M}-\mathrm{H}]^{-}\right)$and verbascoside $\left(623.2008 \mathrm{~m} / z[\mathrm{M}-\mathrm{H}]^{-}\right.$exp.) After six days (Figure $4 \mathrm{~b}$ ), a glycosylated oleuropein derivative appeared, of which the $m / z[\mathrm{M}-\mathrm{H}]^{-}$exp. was 545.1586 . Hydroxytyrosol hexoside (315.1097 [M - H] ${ }^{-}$exp.) and hydroxytyrosol $\left(153.0574[\mathrm{M}-\mathrm{H}]^{-}\right.$exp.) increased, while oleuropein, verbascoside and hydroxyoleuropein decreased. After 14 days (Figure 4c), the oleuropein content was degraded almost completely, while the content of the glycosylated oleuropein derivative compound and the hydroxytyrosol hexoside remained stable. However, hydroxytyrosol began to decline.

On the other hand, the evolution of compounds from olive leaf powder stored at $75 \%$ $\mathrm{RH}$, regardless of temperature, showed instability. Oleuropein, hydroxyoleuropein and verbascoside decreased rapidly, whereas hydroxytyrosol hexoside and hydroxytyrosol were below the limits of detection and did not show an increase over time, as happened in the aqueous extracts. As for the glycosylated oleuropein derivative $(545.1586 \mathrm{~m} / \mathrm{z}$ $[\mathrm{M}-\mathrm{H}]^{-}$exp.) found in the aqueous extracts, it was not found in the olive leaf powder (data not shown). 
(a)

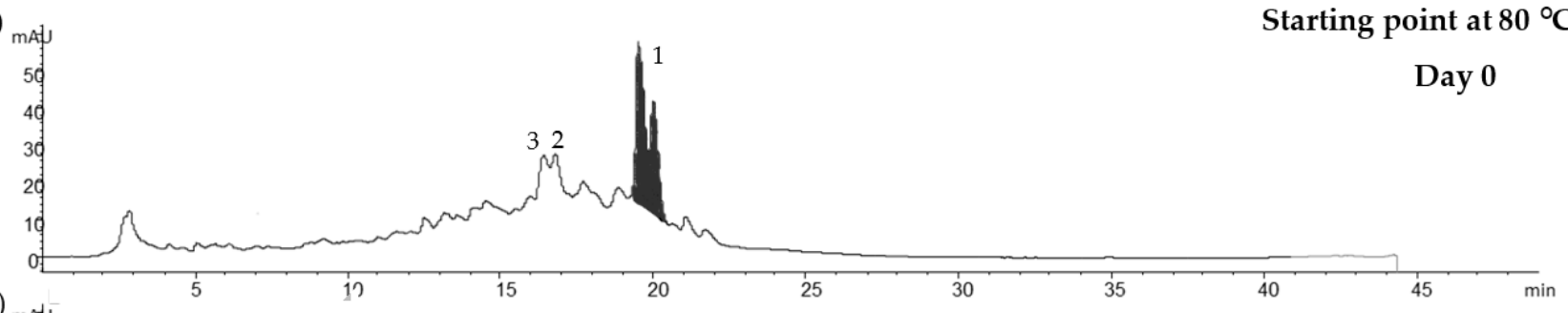

$(\mathbf{b})_{\mathrm{n}}$

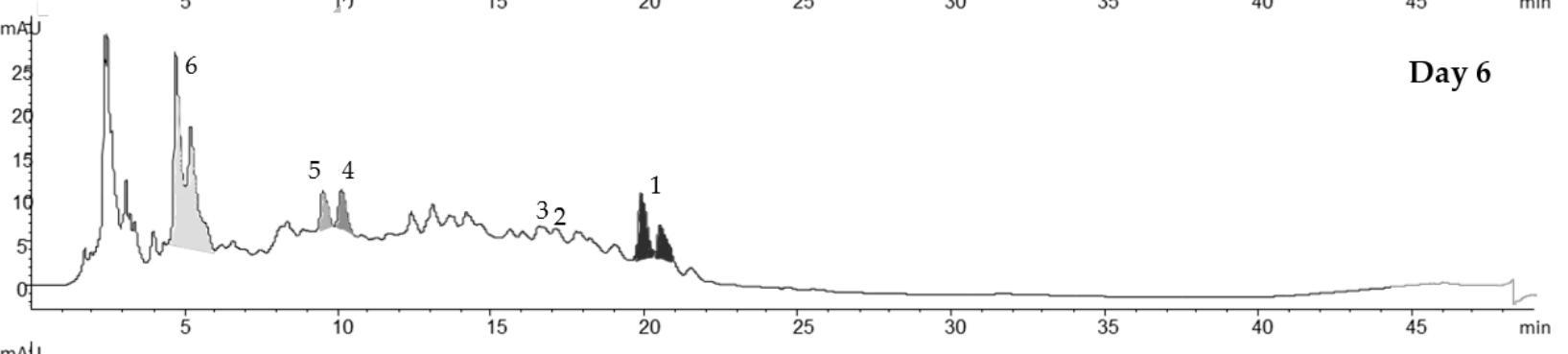

(c)

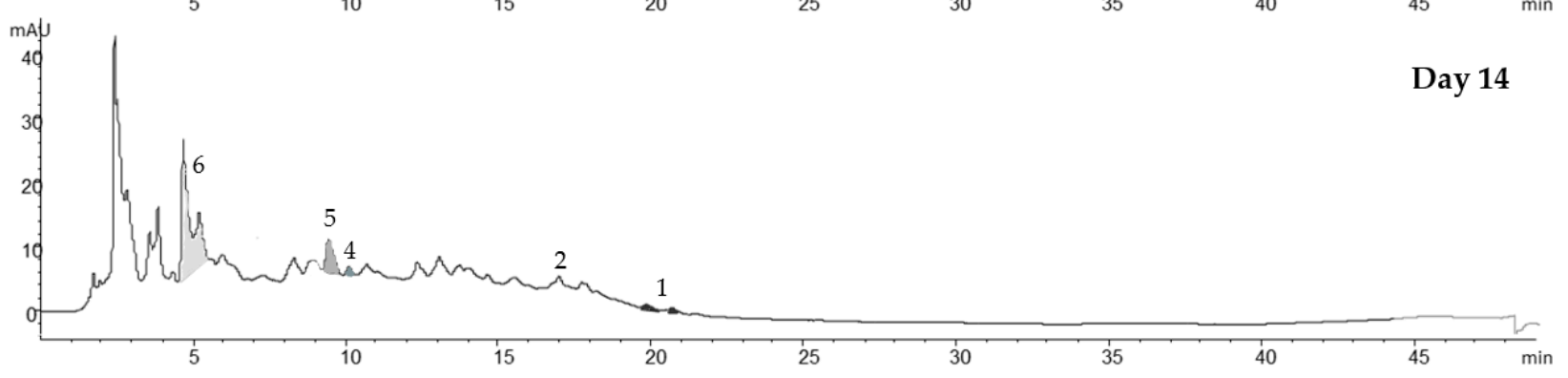

Figure 4. Chromatograms by HPLC-DAD at $280 \mathrm{~nm}$ of aqueous olive leaf extracts stored at $80^{\circ} \mathrm{C}$ : (a) Day 0; (b) Day 6; (c) Day 14, where 1: oleuropein; 2: verbascoside; 3: hydroxyoleuropein; 4: hydroxytyrosol; 5: hydroxytyrosol hexoside; 6: glycosylated oleuropein derivative $\left(545.1586 \mathrm{~m} / z[\mathrm{M}-\mathrm{H}]^{-}\right.$experimental $)$.

\section{Discussion}

The results obtained from the olive leaf powder showed that the RH influenced $(p<0.05)$ the oleuropein content, decreasing it at a higher RH and keeping it stable at a low RH. This second finding is corroborated by the study carried out by Bilgin et al. [18], who observed a decreasing trend of olive leaf polyphenols in humid air. Temperature was a very influential factor in the oleuropein content $(p<0.01)$ of olive leaf powder. High temperatures can also promote the degradation of some phenolic compounds [19], as was seen at $40{ }^{\circ} \mathrm{C}$ and in combination with $\mathrm{RH} \geq 57 \%$. Regarding illumination, some authors have related exposure to sunlight with an increase in phenolic compounds in the olive leaf [20]. In contrast, this study showed no significant differences $(p>0.05)$ between storage in darkness and storage in natural light.

The most unfavourable $\mathrm{RH}$ was $75 \%$, both at $\mathrm{RT}_{\mathrm{S}}$ and $40^{\circ} \mathrm{C}$. The oleuropein content behaved by adjusting to a first-order kinetic model $\left(y_{R T}=88.098 e^{-0.023 x}, \mathrm{R}^{2}=0.986\right.$; $\left.y_{400^{\circ} \mathrm{C}}=58,395 e^{-1.282 x}, \mathrm{R}^{2}=0.9399\right)$. However, the studied temperatures at $75 \% \mathrm{RH}$ showed differences in rate constants $(\mathrm{k})$ and half-life periods $\left(\mathrm{t}_{1 / 2}\right)$. See Table 1.

Table 1. Rate constants $(k)$ and half-life periods $\left(t_{1 / 2}\right)$ of oleuropein content loss in olive leaf powder stored at $75 \% \mathrm{RH}$ at room temperature $\left(\mathrm{RT}_{\mathrm{s}}\right)$ and $40{ }^{\circ} \mathrm{C}$.

\begin{tabular}{ccc}
\hline $\mathbf{T}\left({ }^{\circ} \mathrm{C}\right)$ & $\mathbf{k}\left(\right.$ Days $\left.^{-1}\right)$ & $\mathbf{t}_{\mathbf{1 / 2}}$ (Days) \\
\hline $\mathrm{RT}_{\mathrm{s}}{ }^{1}$ & $0.023 \pm 0.00 \mathrm{a}$ & 30.137 \\
$40{ }^{\circ} \mathrm{C}$ & $1.282 \pm 0.00 \mathrm{~b}$ & 0.541 \\
\hline
\end{tabular}

${ }^{1}$ Room temperature $\left(22.8 \pm 1.9^{\circ} \mathrm{C}\right)$. For each $\mathrm{k}$ value, different small letters indicate significant differences among temperatures according to the Tukey test $(\alpha<0.05)$. The mean values $(n=3)$ are shown with their standard deviation. 
At $\mathrm{RT}_{\mathrm{s}}$, oleuropein content decreased to the level of $19.11 \mathrm{mg} / \mathrm{g}$ in 66 days, while at $40{ }^{\circ} \mathrm{C}$, oleuropein was not detected on Day 29 (Figure 1). In other words, the k value was different $\left(\mathrm{k}_{\mathrm{RT}}=0.023\right.$ and $\left.\mathrm{k}_{40}{ }^{\circ} \mathrm{C}=1.282\right)$, which means that, at $75 \% \mathrm{RH}$ and $\mathrm{RT}_{\mathrm{s}}$, the $\mathrm{t}_{1 / 2}$ was around 30 days, whereas it was approximately $13 \mathrm{~h}$ at $40{ }^{\circ} \mathrm{C}$. During the degradation of the oleuropein content under these conditions, hydroxyoleuropein and verbascoside also decreased rapidly, while the generation of any compound was not observed over time.

By contrast, in aqueous extracts, oleuropein degradation generated other compounds, such as hydroxytyrosol, in the first week of storage. This finding is corroborated by a study carried out by Feng et al. (2021) [21], who observed that, in an olive leaf methanol-water extract, hydroxytyrosol increased in the first week of storage at $25^{\circ} \mathrm{C}$ and then decreased after two weeks. This behaviour was observed in the same way, as it was accentuated with the high-temperatures studies. However, at the beginning of the experiment, hydroxytyrosol was found only as a glycosylate compound: hydroxytyrosol hexoside. In addition, there was also an increase in an unknown compound with an $m / z[\mathrm{M}-\mathrm{H}]^{-}$of 545.1586, and this could be directly correlated with the degradation of oleuropein, which occurred simultaneously. Ahmad-Qasem et al. (2016) [22] studied the storage stability of olive leaf extract (liquid or solid) using ethanol-water $(80: 20 v / v)$. They found that neither the extract form nor the storage temperature affected the phenolic content. However, in this study, storage form, humidity and temperature were key to the stability of the oleuropein content in the olive leaf, although other factors such as enzymatic activities are also involved. These latter factors might be responsible for this decrease in oleuropein and increase in other compounds [19]. De Leonardis et al. (2015) [23] found that at least two types of enzymes, $\beta$-glucosidase and polyphenoloxidase (PPO), were involved in the degradation of endogenous oleuropein in olive leaves. They observed in aqueous extracts of olive leaves at $60{ }^{\circ} \mathrm{C}$ for $24 \mathrm{~h}$ that the oleuropein content disappeared completely and increased, mainly, the aldehydic form of oleuropein aglycon (3,4-DHPEA-EA) due to $\beta$-glucosidase activity. In contrast, this compound was not observed in our study; instead, a glycosylated oleuropein derivative was formed. They also observed that esterases degraded oleuropein to hydroxytyrosol; however, in their study, the latter remained stable, while the one studied in this work decreased, which could be due to PPO activity. On the other hand, the hydroxytyrosol hexoside in this study remained stable, which could be because these two enzymes cannot act on it.

In addition, Briante et al. (2001) [24] studied by different methods the antioxidant capacity of oleuropein and hydroxytyrosol, the latter of which showed slightly superior results in all methods. For example, with the DMPD (N,N-dimethyl-p-phenylenediamine dihydrochloride) method, they obtained 0.60 and 0.79 Trolox equivalents for oleuropein and hydroxytyrosol, respectively. The increase in compounds such as hydroxytyrosol and hydroxytyrosol hexoside in the first week points to a higher antioxidant capacity of the liquid extract. On the other hand, although the hydroxytyrosol hexoside remained stable, the degradation of the hydroxytyrosol after 14 days suggests a decrease in antioxidant capacity. Moreover, the hydroxytyrosol hexoside could be released by enzymatic activities and be a source of hydroxytyrosol with high antioxidant power, which is very interesting for future studies. On the other hand, in the solid form, no increase was observed in any compound other than oleuropein, suggesting that the olive leaf powder format protects the antioxidant potential.

As happened to the olive leaf powder when it was under unfavourable conditions, the aqueous extracts at all temperatures also adjusted to a first-order degradation kinetics (Table 2), showing a lower $t_{1 / 2}$ than the solid form at $\mathrm{RT}_{\mathrm{s}}$.

The temperature of $80^{\circ} \mathrm{C}$ showed the shortest $t_{1 / 2}$ of just over three days, while the one with the longest $t_{1 / 2}$ was the extract stored at $\mathrm{RT}_{1}$ for around 13 days. Although there were no significant differences $(p>0.05)$ between storage at temperatures of $60,40, \mathrm{RT}_{1}$ and $7{ }^{\circ} \mathrm{C}$, the extracts' storage at $\mathrm{RT}_{1}$ ( $\mathrm{t}_{1 / 2}$ of 13 days) was selected as the most suitable due to its easy logistics. 
Table 2. Rate constants $(\mathrm{k})$ and half-life periods $\left(\mathrm{t}_{1 / 2}\right)$ of oleuropein content loss in aqueous extracts from olive leaves at different temperatures $(\mathrm{T})$.

\begin{tabular}{ccc}
\hline $\mathbf{T}\left({ }^{\circ} \mathbf{C}\right)$ & $\mathbf{k}^{\left(\text {Days }^{-1}\right)}$ & $\mathbf{t}_{\mathbf{1 / 2}}$ (Days) \\
\hline 80 & $0.202 \pm 0.00 \mathrm{a}$ & 3.431 \\
60 & $0.077 \pm 0.00 \mathrm{~b}$ & 9.002 \\
40 & $0.068 \pm 0.00 \mathrm{~b}$ & 10.193 \\
$\mathrm{RT}_{1} 1$ & $0.053 \pm 0.00 \mathrm{~b}$ & 13.078 \\
14 & $0.111 \pm 0.00 \mathrm{c}$ & 6.245 \\
7 & $0.075 \pm 0.00 \mathrm{~b}$ & 9.242 \\
\hline
\end{tabular}

${ }^{1}$ Room temperature $\left(24 \pm 1.4{ }^{\circ} \mathrm{C}\right)$. For each $\mathrm{k}$ value, different small letters indicate significant differences among temperatures according to the Tukey test $(\alpha<0.05)$. The mean values $(n=3)$ are shown with their standard deviation.

After calculating the values of $k$ at different temperatures, the activation energy $\left(E_{a}\right)$ for oleuropein degradation was obtained through the Arrhenius Equation [25] (Figure 5). It was observed that, from $80^{\circ} \mathrm{C}$ to $\mathrm{RT}_{1}$, oleuropein degradation was adjusted to a reaction in which $\mathrm{E}_{\mathrm{a}}$ was $12.60 \mathrm{~kJ} / \mathrm{mol}$. Cold temperatures (from 14 to $7^{\circ} \mathrm{C}$ ) exhibited a different behaviour, thus indicating that a different degradation reaction took place. The latter behaviour has been observed in other antioxidant compounds [15], as the rate of reaction depends on the temperatures.

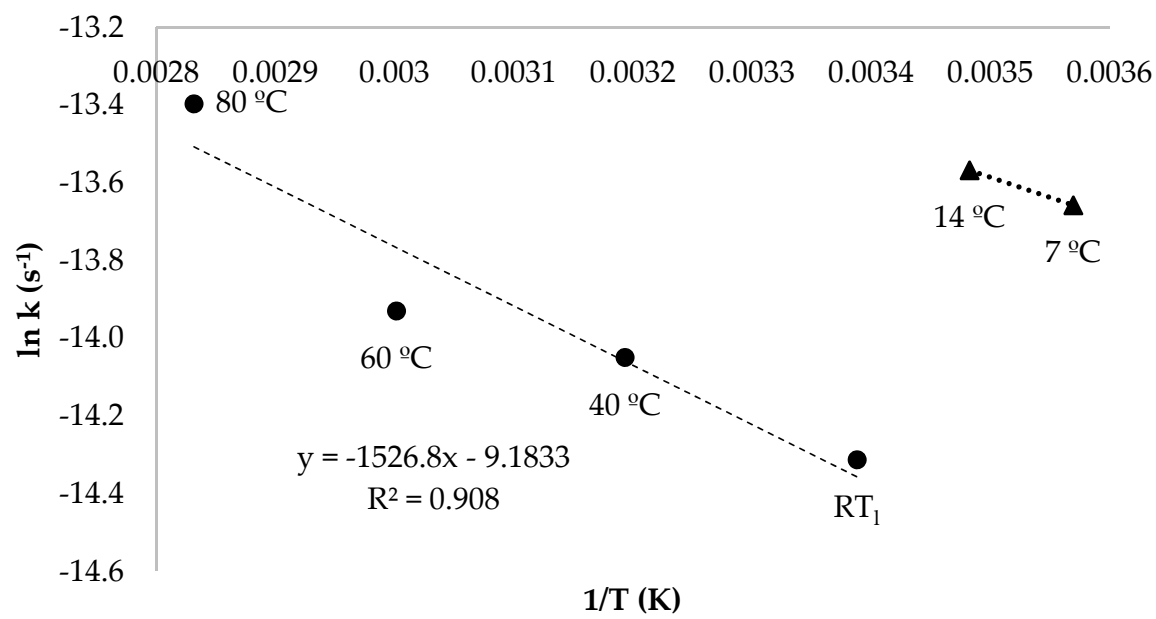

Figure 5. Linear dependence of natural logarithm of the rate constant $\left(\ln k, s^{-1}\right)$ with respect to the inverse of the temperature $(1 / \mathrm{T}, \mathrm{K})$ of oleuropein content from aqueous extracts stored between temperatures of $80^{\circ} \mathrm{C}$ to $\mathrm{RT}_{1}\left(24 \pm 1.4^{\circ} \mathrm{C}\right)$ and 14 to $7^{\circ} \mathrm{C}$.

Regarding the decrease in $\mathrm{pH}$ observed in the liquid extracts under storage at $80{ }^{\circ} \mathrm{C}$ from 6.30 to 4.42 , it is normal that hydroxytyrosol and elenolic acid are released into the medium when oleuropein is degraded. The latter acid may be largely responsible for the decrease in $\mathrm{pH}$, which is attenuated in the other temperatures; however, such acid has not been detected with this method.

\section{Conclusions}

The temperature, $\mathrm{RH}$ and storage form affected the stability of oleuropein content from olive leaves, while illumination had no effect. The degradation process of oleuropein showed better fits in a first order kinetic model with an $\mathrm{E}_{\mathrm{a}}$ of $12.60 \mathrm{~kJ} / \mathrm{mol}$ from $80^{\circ} \mathrm{C}$ to $\mathrm{RT}_{1}$.

Among the storage conditions studied, that which best prevented oleuropein loss was the storage of olive leaf powder below $57 \% \mathrm{RH}$ at $\mathrm{RT}_{\mathrm{s}}$, as the aqueous extracts were more unstable.

The degradation process of oleuropein in aqueous extracts showed similar trends, with the decrease in oleuropein during the first hours followed by an increase in the first 
week of a glycosylated oleuropein derivative, hydroxytyrosol hexoxide and especially hydroxytyrosol. In the second week, hydroxytyrosol decreased and the glycosylated oleuropein derivative and hydroxytyrosol hexoxide remained stable. In contrast, the degradation of olive leaf powder stored at 75\% RH was as follows: oleuropein decreased, and the compounds that increase in the aqueous extracts were not detected. Therefore, olive leaf powder stored in environmental conditions could constitute an interesting opportunity for the olive sector through the re-evaluation of olive leaves transforming them from waste to by-product.

Author Contributions: Conceptualization, M.E.M.-N., C.C.-T., J.O., M.R.S. and G.L.A.; methodology, M.E.M.-N., C.C.-T., J.O., M.R.S. and G.L.A.; software, M.E.M.-N. and C.C.-T.; validation, M.E.M.-N. and C.C.-T.; for-mal analysis, M.E.M.-N. and C.C.-T.; investigation, M.E.M.-N.; resources, M.E.M.N., C.C.-T., J.O., M.R.S. and G.L.A.; data curation, M.E.M.-N. and C.C.-T.; writing-original draft preparation, M.E.M.-N., C.C.-T., J.O., M.R.S. and G.L.A.; writing-review and editing, M.E.M.-N., C.C.-T., J.O., M.R.S. and G.L.A.; visualization, M.E.M.-N., C.C.-T., J.O., M.R.S. and G.L.A.; supervision, G.L.A. and M.R.S.; project administration, G.L.A. and M.R.S.; funding acquisition, G.L.A. and M.R.S. All authors have read and agreed to the published version of the manuscript.

Funding: This research received not external funding.

Institutional Review Board Statement: Not applicable.

Informed Consent Statement: Not applicable.

Data Availability Statement: Data is contained within the article.

Acknowledgments: M. E. Martínez-Navarro wishes to thank the Universidad de Castilla-La Mancha for the predoctoral contract 2019-PREDUCLM. We thank the Government of Castilla-La Mancha (Spain) in collaboration with FEDER for financing the project SBPLY/17/180501/000191 and the owner of the oil mill for his collaboration.

Conflicts of Interest: The authors declare that they have no known competing financial interests or personal relationships that could have appeared to influence the work reported in this paper.

\section{References}

1. Lama-Muñoz, A.; Contreras, M.d.M.; Espínola, F.; Moya, M.; Romero, I.; Castro, E. Content of phenolic compounds and mannitol in olive leaves extracts from six Spanish cultivars: Extraction with the Soxhlet method and pressurized liquids. Food Chem. 2020, 320, 126626. [CrossRef]

2. Ruiz, E.; Romero-García, J.M.; Romero, I.; Manzanares, P.; Negro, M.J.; Castro, E. Olive-derived biomass as a source of energy and chemicals. Biofuels Bioprod. Biorefining 2017, 11, 1077-1094. [CrossRef]

3. Kermanshah, Z.; Samadanifard, H.; Moghaddam, O.M.; Hejrati, A. Olive leaf and its various health-benefitting effects: A review study. Pak. J. Med Health Sci. 2020, 14, 1301-1312.

4. Martínez-Navarro, E.M.; Cebrián-Tarancón, C.; Moratalla-López, N.; Lorenzo, C.; Alonso, G.L.; Salinas, R.M. Development and validation of an HPLC-DAD method for determination of oleuropein and other bioactive compounds in olive leaf by-products. J. Sci. Food Agric. 2021, 101, 1447-1453. [CrossRef] [PubMed]

5. Martínez, L.; Castillo, J.; Ros, G.; Nieto, G. Antioxidant and Antimicrobial Activity of Rosemary, Pomegranate and Olive Extracts in Fish Patties. Antioxidants 2019, 8, 86. [CrossRef]

6. Lins, P.G.; Marina Piccoli Pugine, S.; Scatolini, A.M.; de Melo, M.P. In vitro antioxidant activity of olive leaf extract (Olea europaea L.) and its protective effect on oxidative damage in human erythrocytes. Heliyon 2018, 4, e00805. [CrossRef] [PubMed]

7. Martínez, L.; Ros, G.; Nieto, G. Hydroxytyrosol: Health Benefits and Use as Functional Ingredient in Meat. Medicines 2018, 5, 13. [CrossRef]

8. Medina, E.; Romero, C.; Garcia, P.; Brenes, M. Characterization of bioactive compounds in commercial olive leaf extracts, and olive leaves and their infusions. Food Funct. 2019, 10, 4716-4724. [CrossRef]

9. Khan, H.; Ahmad, W.; Hussain, I.; Imran, M.; Afridi, M.S.; Ullah, S. Phytochemical composition, antioxidant and antimicrobial activities of leaves of Olea europaea wild variety. J. Food Meas. Charact. 2020, 14, 640-648. [CrossRef]

10. Cavaca, L.A.S.; López-Coca, I.M.; Silvero, G.; Afonso, C.A.M. Chapter 5-The olive-tree leaves as a source of high-added value molecules: Oleuropein. In Studies in Natural Products Chemistry; Atta Ur, R., Ed.; Elsevier: Amsterdam, The Netherlands, 2020; Volume 64, pp. 131-180.

11. Cádiz-Gurrea, M.d.l.L.; Pinto, D.; Delerue-Matos, C.; Rodrigues, F. Olive Fruit and Leaf Wastes as Bioactive Ingredients for Cosmetics-A Preliminary Study. Antioxidants 2021, 10, 245. [CrossRef] 
12. Barbaro, B.; Toietta, G.; Maggio, R.; Arciello, M.; Tarocchi, M.; Galli, A.; Balsano, C. Effects of the olive-derived polyphenol oleuropein on human health. Int. J. Mol. Sci. 2014, 15, 18508-18524. [CrossRef]

13. Commission Regulation (EU) No 432/2012 of 16 May 2012 Establishing a List of Permitted Health Claims Made on Foods, Other Than Those Referring to the Reduction of Disease Risk and to Children's Development and Health. Available online: https:/ / eur-lex.europa.eu/eli/reg/2012/432/oj (accessed on 7 December 2020).

14. Moratalla-López, N.; Lorenzo, C.; Chaouqi, S.; Sánchez, A.M.; Alonso, G.L. Kinetics of polyphenol content of dry flowers and floral bio-residues of saffron at different temperatures and relative humidity conditions. Food Chem. 2019, 290, 87-94. [CrossRef] [PubMed]

15. Sánchez, A.M.; Carmona, M.; Jarén-Galán, M.; Mínguez Mosquera, M.I.; Alonso, G.L. Picrocrocin Kinetics in Aqueous Saffron Spice Extracts (Crocus sativus L.) upon Thermal Treatment. J. Agric. Food Chem. 2011, 59, 249-255. [CrossRef]

16. Serrano-Díaz, J.; Sánchez, A.M.; Martínez-Tomé, M.; Winterhalter, P.; Alonso, G.L. Flavonoid Determination in the Quality Control of Floral Bioresidues from Crocus sativus L. J. Agric. Food Chem. 2014, 62, 3125-3133. [CrossRef] [PubMed]

17. Zuo, Y.; Chen, H.; Deng, Y. Simultaneous determination of catechins, caffeine and gallic acids in green, Oolong, black and pu-erh teas using HPLC with a photodiode array detector. Talanta 2002, 57, 307-316. [CrossRef]

18. Bilgin, M.; Şahin, S. Effects of geographical origin and extraction methods on total phenolic yield of olive tree (Olea europaea) leaves. J. Taiwan Inst. Chem. Eng. 2013, 44, 8-12. [CrossRef]

19. Şahin, S.; Bilgin, M. Olive tree (Olea europaea L.) leaf as a waste by-Product of table olive and olive oil industry: A review. J. Sci. Food Agric. 2018, 98, 1271-1279. [CrossRef]

20. Talhaoui, N.; Taamalli, A.; Gómez-Caravaca, A.M.; Fernández-Gutiérrez, A.; Segura-Carretero, A. Phenolic compounds in olive leaves: Analytical determination, biotic and abiotic influence, and health benefits. Food Res. Int. 2015, 77, 92-108. [CrossRef]

21. Feng, S.; Zhang, C.; Liu, L.; Zhou, X.; Chen, T.; Zhou, L.; Yuan, M.; Li, T.; Ding, C. Comparison of Phenolic Compounds in Olive Leaves by Different Drying and Storage Methods. Separations 2021, 8, 156. [CrossRef]

22. Ahmad-Qasem, M.H.; Ahmad-Qasem, B.H.; Barrajón-Catalán, E.; Micol, V.; Cárcel, J.A.; García-Pérez, J.V. Drying and storage of olive leaf extracts. Influence on polyphenols stability. Ind. Crop. Prod. 2016, 79, 232-239. [CrossRef]

23. De Leonardis, A.; Macciola, V.; Cuomo, F.; Lopez, F. Evidence of oleuropein degradation by olive leaf protein extract. Food Chem. 2015, 175, 568-574. [CrossRef] [PubMed]

24. Briante, R.; La Cara, F.; Tonziello, M.P.; Febbraio, F.; Nucci, R. Antioxidant Activity of the Main Bioactive Derivatives from Oleuropein Hydrolysis by Hyperthermophilic $\beta$-Glycosidase. J. Agric. Food Chem. 2001, 49, 3198-3203. [CrossRef] [PubMed]

25. Gikas, E.; Papadopoulos, N.; Tsarbopoulos, A. Kinetic study of the acidic hydrolysis of oleuropein, the major bioactive metabolite of olive oil. J. Liq. Chromatogr. Relat. Technol. 2006, 29, 497-508. [CrossRef] 